\title{
Development of fast dissolving tablets of flurbiprofen by sublimation method and its in vitro evaluation
}

\author{
Nabeela Shaheen ${ }^{1, *}$, Shahiq uz Zaman ${ }^{1}$ \\ ${ }^{1}$ Department of Pharmaceutics, Riphah Institute of Pharmaceutical Sciences, Riphah International University, Islamabad, \\ Pakistan
}

\begin{abstract}
Flurbiprofen belongs to Biopharmaceutical Classification System (BCS) class II drugs which are poorly soluble in water. The objective of present research work was to prepare fast dissolving tablets of Flurbiprofen using varying concentrations of three different sublimating agents to improve the dissolution rate. Seven formulations were prepared containing different concentrations of camphor, ammonium bicarbonate and thymol as sublimating agent along with primogel as a superdisintegrant. Tablets were manufactured by direct compression method. The prepared tablets were evaluated for pre-compression and post-compression parameters result, For all formulations result was within official limits. FTIR studies revealed that there were no interactions between the drug and the excipients used. From in vitro drug release studies it was concluded that the formulations F6 and F7 containing $10 \%$ and $15 \%$ of thymol showed fast drug release of $100.00 \%$ and $100.84 \%$ respectively in 30 minutes. Formulations containing camphor (F2 \& F3) and ammonium bicarbonate (F4 \& F5) as sublimating agents showed a drug release of less than $80 \%$, while the control formulation F1 having no sublimating agent showed $49.14 \%$ of drug release in 30 minutes. Thus thymol can successfully be used to formulate fast dissolving tablets of flurbiprofen by sublimation method with much better dissolution profile.
\end{abstract}

Keywords: Flurbiprofen/dissolution. Fast dissolving tablets. Drug release. Sublimating agent. Superdisintegrant.

\section{INTRODUCTION}

Most appropriate route for drug administration is oral route because of versatility, simplicity of intake and most importantly patient compliance. Fast dissolving tablets are acquiring eminence as modern system of drug delivery because disintegration time of such formulations is within seconds to minutes (El-Enin, 2014). Fast dissolving tablets are very beneficial in administration of drugs to children; bedridden patients, in patients having dysphagia, stroke, thyroid disorder, Parkinson's diseases and multiple sclerosis, patients with nausea, vomiting and motion sickness leading to improved patient compliance (Kuchekar, Badhan, Mahajan, 2003). Rate of drug dissolution can be enhanced by different methods which include Direct compression, Wet granulation, Molding, Spray drying, Freeze drying, Lyophilisation

\footnotetext{
*Correspondence: N. Shaheen. Department of Pharmaceutics, Riphah Institute of Pharmaceutical Sciences; Riphah International, University Islamabad Pakistan. E-mail: nabeelashaheen.shaheen26@gmail.com
}

and Sublimation (Mettu, Veerareddy, 2013; Nagar et al., 2011).

The main objective of preparation of Fast Dissolving Tablets (FDT's) is to prepare a porous matrix of tablets. In sublimation technique for the preparation of such a porous structure various highly volatile ingredients like ammonium bicarbonate, ammonium carbonate, benzoic acid, camphor, naphthalene, urea, urethane, thymol and phthalic anhydride etc are incorporated in the formulation. Different solvents can also be used for formation of porous matrix, these solvents include cyclohexane, benzene and many others (Goel et al., 2008). In this study sublimation technique was employed for designing seven formulations of Flurbiprofen FDT's by use of varying proportions of camphor, ammonium bicarbonate and thymol as sublimating agents.

\section{MATERIAL AND METHODS}

Flurbiprofen, thymol, camphor, ammonium bicarbonate were received as a gift from Medizan 
Laboratories and all the other ingredients used were of analytical grade.

\section{Manufacturing of the tablets}

Seven formulations (F1, F2, F3, F4, F5, F6 and F7) of Flurbiprofen (FLB) tablets were designed in such a way that $\mathrm{F} 1$ was control containing no sublimating agent. Formulation F2 and F3 contained $10 \%$ and $15 \%$ of camphor respectively as sublimating agent, F4 and F5 contained $10 \%$ and $15 \%$ of ammonium bicarbonate, while F6 and F7 contained $10 \%$ and $15 \%$ of thymol as sublimating agent.

Accurately weighed quantity of each excipient was mixed except magnesium stearate and talcum and passed through sieve \#60. After sufficient mixing accurately weighed quantity of magnesium stearate and talcum were added for lubrication (Vemula, Neduri, 2015). The compositions of the formulations are presented in Table I.

After this, powder mixture of each formulation was evaluated for angle of repose, bulk density, tapped density. The fixed funnel method was employed to measure the angle of repose $(\theta)$ and it was calculated using the following formula:

$$
\operatorname{Tan} \theta=h / r
$$

where, $\theta$ is angle of repose, $h$ is height of the cone, and $r$ is radius of the cone base.

Powder was mixed properly and approximately $2 \mathrm{~g}$ of finely mixed powder was added in a funnel which was then set in such a way that lower tip of funnel slightly touches the peak of powder heap. Funnel was set on plane surface and powder was passed freely through it. Measurement of diameter was then done and calculations were done according to above equation (Neduri, Bontha, Vemula, 2013). Bulk density was measured by taking $2 \mathrm{~g}$ of properly mixed powder of each formulation into $10 \mathrm{~mL}$ of graduated measuring cylinder and powder volume was observed (Neduri, Bontha, Vemula, 2013). For measuring tapped density cylinder was tapped on a hard surface after every 2 seconds and this procedure was repeated until no change in volume was observed. Final volume of powder was then measured. The compressibility index was determined from the bulk and tapped densities and was calculated using the following formula:

Compressibility index $=($ Tapped Density-Bulk density $) /$ Tapped Density $x 100$

After pre-compression studies the powder blend of each formulation was compressed using compression machine ZP 17 with punch size of $12 \mathrm{~mm}$. Finally the prepared tablets (except F1) were heated in a hot air oven at $60^{\circ} \mathrm{C}$ for 2 hours for removing sublimating agent until constant weight of tablet was achieved.

\section{Post-compression parameters of the tablets}

The prepared tablets were studied for post compression parameters like weight variation, hardness and friability. For estimating weight variation, 20 tablets of each formulation were weighed using an analytical weighing balance (Shimadzu, UX 420H). The strength of tablet is expressed by measuring hardness and friability. The hardness of six tablets was measured using Monsanto tablet hardness tester. Friability of ten tablets was determined using Roche friabilator for $4 \mathrm{~min}$ at $25 \mathrm{rpm}$.

\section{Disintegration time}

It was calculated by the use of USP disintegration test apparatus. This apparatus consists of a basket rack containing 6-open-ended glass tubes held in a vertical position. A number 10-mesh stainless steel wire screen is attached to the bottom. To test for disintegration time, one tablet from each formulation was individually added into the basket of disintegration apparatus and temperature was set at $37+2{ }^{\circ} \mathrm{C}$. Finally time required for complete disintegration was recorded (Kumar et al., 2009).

\section{Wetting time and water absorption ratio}

One tablet selected from each formulation was placed in a Petri plate with internal diameter of $10 \mathrm{~cm}$, having circular tissue paper folded twice. $0.5 \%(\mathrm{w} / \mathrm{v})$ of phenol red was added in $10 \mathrm{~mL}$ of water and this solution was then poured into petri plate and after complete wetting, time was noted using stop watch. For determination of water absorption ratio same test was conducted without using phenol red. Calculation of Water absorption ratio (R) was done according to formula given below (Vemula, Reddy, 2015).

$$
\mathbf{R}=\mathbf{W}_{\mathrm{a}}-\mathbf{W}_{\mathrm{b}} / \mathbf{W}_{\mathrm{b}} \times 100
$$

$\mathrm{W}_{\mathrm{a}}$ represent weight of tablet after wetting, while $\mathrm{W}_{\mathrm{b}}$ represent weight of tablet before wetting.

\section{Dispersion time}

From each formulation one tablet was selected 
randomLy and time in which the tablet gets dispersed entirely was noted. For this purpose $10 \mathrm{~mL}$ of water was added in a glass beaker and tablet was added into it. Finally dispersion time was observed and noted using stop watch. The results were recorded in triplicates (Jadhav et al., 2011).

\section{Analysis of drug content}

For preparation of sample solution 10 tablets from each formulation were randomLy selected and crushed into fine powder by using pestle and mortar. This fine powder blend equivalent to $100 \mathrm{mg}$ of flurbiprofen was then added in $100 \mathrm{~mL}$ of $0.1 \mathrm{~N} \mathrm{NaOH}$ and sonicated for 30 minutes. After filtration determination of drug content was done with UV spectrophotometer at $247 \mathrm{~nm}$ (Javed et al., 2013).

\section{In vitro dissolution study}

Flurbiprofin dissolution study was carried out using dissolution type II apparatus. This test was conducted for 45 minutes in $900 \mathrm{~mL}$ of $0.1 \mathrm{~N} \mathrm{HCl}$ at $37 \pm 0.5^{\circ} \mathrm{C}$ and $50 \mathrm{rpm}$. In vitro release was determined by collecting $5 \mathrm{~mL}$ of sample after $0,5,10,15,20,25,30,35,40,45$ minutes and replacing with fresh media. These samples were analysed by UV-visible spectrophotometer at $247 \mathrm{~nm}$ (Valleri et al., 2004).

\section{Kinetics of drug release}

For determination of kinetics of drug release for each formulation of FDTs, Zero-order, First-order, Higuchi's,
Hixson \& Crowell and Korsemeyer Peppas equations were applied on data (Neau et al., 1999; Makhija, Vavia, 2002).

\section{Statistical analysis of data}

For determination of significant difference in drug release kinetics of different formulations statistical tests including ANOVA and t-test were applied.

\section{Fourier transform infrared spectroscopy (FTIR)}

Infrared spectroscopy of pure FLB, active ingredient plus excipients blend of all the formulations was carried out using FTIR spectrophotometer. The spectra were scanned over a frequency range of 3500 to $1000 \mathrm{~cm}^{-1}$ (Mettu, Veerareddy, 2013).

\section{Stability studies}

For assessment of stability of active and final formulations, ICH guidelines were followed and stability studies were carried out accordingly. All the samples were carefully packed in aluminium foil and kept in humidity chamber set at temperature and humidity conditions of $40 \pm 2{ }^{\circ} \mathrm{C}$ and $75 \pm 5 \% \mathrm{RH}$ respectively for one month (Vemula, Neduri, 2015).

\section{RESULTS AND DISCUSSION}

\section{Pre-compression parameters}

Each formulation blend of drug and excipients

TABLE I - Composition of formulations prepared by sublimation technique

\begin{tabular}{|c|c|c|c|c|c|c|c|}
\hline \multirow{2}{*}{ Excipients (mg/tab) } & \multicolumn{7}{|c|}{ Formulations } \\
\hline & F1 & F2 & F3 & F4 & F5 & F6 & F7 \\
\hline Flurbiprofen & 100 & 100 & 100 & 100 & 100 & 100 & 100 \\
\hline Microcrystalline cellulose(102) & 243 & 198 & 175.5 & 198 & 175.5 & 198 & 175.5 \\
\hline Lactose SD & 35 & 35 & 35 & 35 & 35 & 35 & 35 \\
\hline Primogel & 20 & 20 & 20 & 20 & 20 & 20 & 20 \\
\hline Colloidal silicon dioxide & 4 & 4 & 4 & 4 & 4 & 4 & 4 \\
\hline Thymol & - & - & - & - & - & 45 & 67.5 \\
\hline Camphor & - & 45 & 67.5 & - & - & - & - \\
\hline Ammonium bicarbonate & - & - & - & 45 & 67.5 & - & - \\
\hline Mannitol & 30 & 30 & 30 & 30 & 30 & 30 & 30 \\
\hline Talcum & 8 & 8 & 8 & 8 & 8 & 8 & 8 \\
\hline Magnesium stearate & 10 & 10 & 10 & 10 & 10 & 10 & 10 \\
\hline Net weight & 450 & 450 & 450 & 450 & 450 & 450 & 450 \\
\hline
\end{tabular}


prepared were evaluated for angle of repose, bulk density, tapped density and compressibility index. Bulk density was found in the range of $\mathbf{0 . 3 5 - 0 . 4 5} \mathrm{g} / \mathrm{mL}$ and tapped density between $\mathbf{0 . 3 9 - 0 . 5 0} \mathrm{g} / \mathbf{m L}$. Angle of repose was also evaluated which was between 24.36 and 30.50. The powder blends of all the formulations had compressibility index between $\mathbf{1 0 . 0 1}$ and $\mathbf{1 3 . 3 2}$ as shown in Table II. The results indicated that the powder blends possessed ideal properties required to be produced by direct compression method.

\section{Post-compression parameters}

Flurbiprofen fast dissolving tablets were prepared in seven formulations (F1 was control having no sublimating agent) by compressing powder blend using direct compression technique. The data obtained from post-compression parameters such as thickness, hardness, friability, weight variation, amount of drug content, wetting time, water absorption ratio and disintegration time are shown in Table III.

Tablet hardness values lied between $\mathbf{5 . 0} \pm \mathbf{0 . 2 1}$ to $5.4 \pm 0.33 \mathrm{~kg} / \mathrm{cm}^{2}\left(\right.$ acceptance range $\left.=5-8 \mathrm{~kg} / \mathrm{cm}^{2}\right)$ for all the formulations indicating good mechanical strength with an ability to withstand physical and mechanical stress conditions while handling. Thickness value of tablets lied between $3.20 \pm 0.05$ to $3.24 \pm \mathbf{0 . 0 6} \mathbf{~ m m}$ (acceptance range $= \pm \mathbf{5 \%}$ ). In all the formulations the friability values were less than $1 \%$ and met the Pharmacopoeial limits. The loss of percentage of weight of all the formulations in friability was $0.41 \pm \mathbf{0 . 0 2}$ to0.58 $\pm \mathbf{0 . 0 6}$ which was well below the allowed official limits.

Wetting time of tablets prepared from sublimation technique ranged from $51 \pm 0.49$ to $56 \pm 0.85$ seconds. Dispersion time values were found in the range from $\mathbf{5 4}$ \pm 0.24 to $61 \pm 0.47$ seconds. Results of disintegration test lied between $40 \pm 0.79$ to $46 \pm 0.25$ seconds (acceptable disintegration time standards are 5 minutes). The results

TABLE II - Pre-compression parameters of the formulations

\begin{tabular}{|c|c|c|c|c|c|}
\hline Formulations & $\begin{array}{c}\text { Bulk Density } \\
(\mathrm{g} / \mathrm{mL}) \pm \text { S.D } \\
(\mathrm{n}=\mathbf{3})\end{array}$ & $\begin{array}{c}\text { Tapped Density } \\
(\mathrm{g} / \mathbf{m L}) \pm \text { S.D } \\
(\mathbf{n}=\mathbf{3})\end{array}$ & $\begin{array}{c}\text { Hausner's } \\
\text { Ratio } \pm \text { S.D } \\
(\mathrm{n}=\mathbf{3})\end{array}$ & $\begin{array}{c}\text { Angle of } \\
\text { Repose } \pm \text { S.D } \\
(n=3)\end{array}$ & $\begin{array}{c}\text { Compressibility } \\
\text { Index }(\%) \pm \text { S.D } \\
(\mathbf{n}=\mathbf{3})\end{array}$ \\
\hline F 1 & $0.43 \pm 0.025$ & $0.49 \pm 0.042$ & $1.12 \pm 0.037$ & $26.66 \pm 0.73$ & $11.51 \pm 0.76$ \\
\hline F 2 & $0.36 \pm 0.033$ & $0.42 \pm 0.074$ & $1.14 \pm 0.038$ & $25.10 \pm 0.71$ & $13.32 \pm 0.79$ \\
\hline F 3 & $0.35 \pm 0.033$ & $0.39 \pm 0.012$ & $1.10 \pm 0.031$ & $24.36 \pm 0.68$ & $10.01 \pm 0.42$ \\
\hline F 4 & $0.45 \pm 0.041$ & $0.51 \pm 0.017$ & $1.18 \pm 0.046$ & $25.24 \pm 0.70$ & $12.85 \pm 0.62$ \\
\hline F 5 & $0.37 \pm 0.022$ & $0.42 \pm 0.074$ & $1.15 \pm 0.039$ & $30.31 \pm 0.60$ & $11.08 \pm 0.42$ \\
\hline F 6 & $0.45 \pm 0.041$ & $0.51 \pm 0.017$ & $1.15 \pm 0.039$ & $29.89 \pm 0.61$ & $12.87 \pm 0.68$ \\
\hline F7 & $0.45 \pm 0.041$ & $0.50 \pm 0.017$ & $1.10 \pm 0.031$ & $30.50 \pm 0.60$ & $10.94 \pm 0.43$ \\
\hline
\end{tabular}

TABLE III - Post compression parameters of the formulations

\begin{tabular}{|c|c|c|c|c|c|c|c|c|}
\hline Sr. & Parameters & F 1 & F 2 & F 3 & F 4 & F 5 & F6 & F7 \\
\hline 1 & $\begin{array}{c}\text { Hardness }\left(\mathrm{kg} / \mathrm{cm}^{2}\right) \pm \\
\mathrm{SD}, \mathrm{n}=3\end{array}$ & $5.4 \pm 0.33$ & $5.2 \pm 0.29$ & $5.0 \pm 0.21$ & $5.1 \pm 0.14$ & $5.0 \pm 0.20$ & $5.1 \pm 0.14$ & $5.0 \pm 0.24$ \\
\hline 2 & $\begin{array}{c}\text { Thickness }(\mathrm{mm}) \pm \\
\text { SD, } \mathrm{n}=3\end{array}$ & $3.21 \pm 0.04$ & $3.23 \pm 0.03$ & $3.23 \pm 0.05$ & $3.20 \pm 0.09$ & $3.20 \pm 0.05$ & $3.24 \pm 0.06$ & $3.21 \pm 0.09$ \\
\hline 3 & $\begin{array}{c}\text { Friability }(\% \mathrm{w} / \mathrm{w}) \pm \\
\mathrm{SD}, \mathrm{n}=3\end{array}$ & $0.58 \pm 0.06$ & $0.41 \pm 0.04$ & $0.43 \pm 0.08$ & $0.41 \pm 0.02$ & $0.48 \pm 0.04$ & $0.43 \pm 0.02$ & $0.51 \pm 0.09$ \\
\hline 4 & $\begin{array}{l}\text { Disintegration Time } \\
(\mathrm{Sec}) \pm \mathrm{SD}, \mathrm{n}=3\end{array}$ & $46 \pm 0.25$ & $43 \pm 0.21$ & $45 \pm 0.49$ & $43 \pm 0.57$ & $45 \pm 0.40$ & $40 \pm 0.79$ & $41 \pm 0.73$ \\
\hline 5 & $\begin{array}{c}\text { Wetting Time }(\mathrm{Sec}) \pm \\
\text { SD, } \mathrm{n}=3\end{array}$ & $56 \pm 0.85$ & $55 \pm 0.11$ & $56 \pm 0.14$ & $54 \pm 0.36$ & $51 \pm 0.49$ & $56 \pm 0.50$ & $54 \pm 0.32$ \\
\hline 6 & $\begin{array}{c}\text { Dispersion Time (Sec) } \\
\pm \mathrm{SD}, \mathrm{n}=3\end{array}$ & $54 \pm 0.55$ & $58 \pm 0.91$ & $54 \pm 0.45$ & $61 \pm 0.21$ & $60 \pm 0.26$ & $61 \pm 0.47$ & $54 \pm 0.24$ \\
\hline 7 & Drug Content & $100.03 \%$ & $99.97 \%$ & $100.03 \%$ & $99.99 \%$ & $99.98 \%$ & $99.99 \%$ & $100.02 \%$ \\
\hline
\end{tabular}


of wetting time and disintegration time of all the tablets were found to be within the prescribed limits and satisfied the criteria of fast dissolving tablets. All the formulations possessed acceptable hardness, friability, wetting time and disintegration time which is an absolute requirement for any fast dissolving tablet.

From the dissolution studies, cumulative percentage of drug release versus time was evaluated as presented in Figure 1. Figure 1 represents the percentage release of all the formulations against time. It also reflects that the formulations F6 and F7 containing $45 \mathrm{mg}$ and $67.5 \mathrm{mg}$ of thymol respectively showed fast drug release of $100.00 \%$ and $100.84 \%$ respectively in 30 minutes as compared with formulations containing other sublimating agents. Among all the formulations, F6 and F7 tablets showed complete drug release within 30 minutes and rapid dissolution. The possible reasons and mechanisms for increased dissolution rates are formation of porous structure on the surface of tablet due to sublimation and the presence of superdisintegrants which enhance the water permeation (wicking action) into the tablet, which leads to a prompt wetting action, short disintegration time and finally causes the fast dissolution rate. It was observed that as the concentration of sublimating agents was increased the drug release also increased, because as the concentration of sublimating agent increases, there will be more number of pores formed

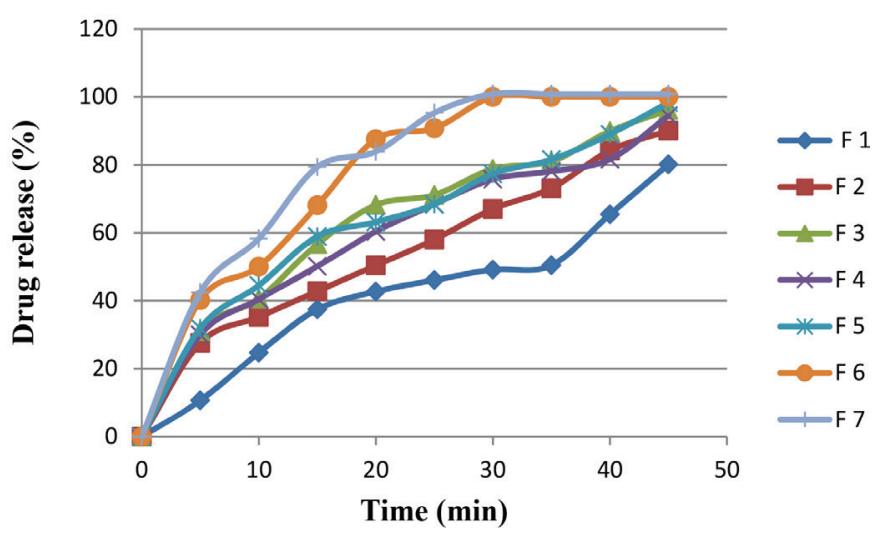

FIGURE 1 - Drug release (\%) of formulations versus time (min). in the tablet, because of which water can enter and get absorbed in more quantity, which will lead to rapid disintegration.

Drug release rates obtained for the formulations were subjected for kinetic treatment to know the order of drug release rates. Values of the drug release were attempted to fit into various mathematical models to observe the mechanism as showed in Table IV. The correlation coefficient values were obtained for all the five models. Model fitting plots of the optimized formulations best suited Krosmeyers-Peppas release kinetics as shown in Figure 2- Figure 6.

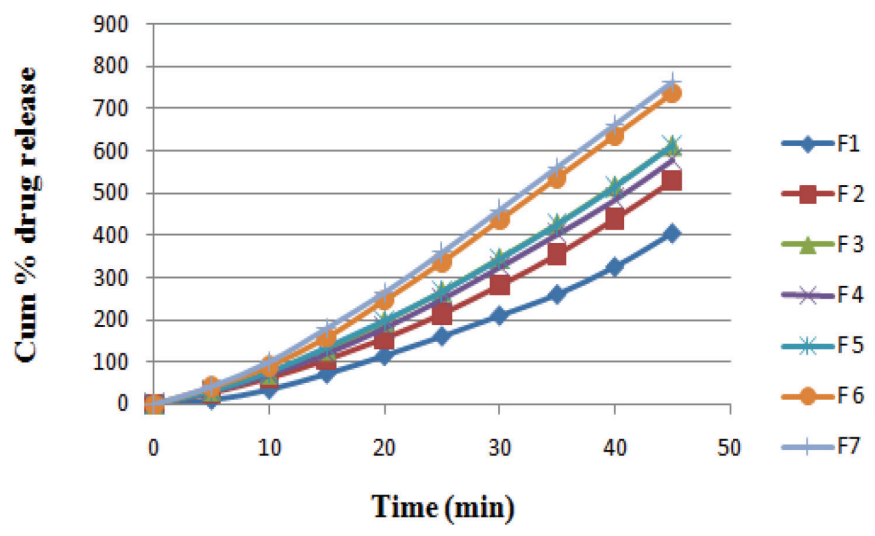

FIGURE 2 - Zero order release kinetics plot.

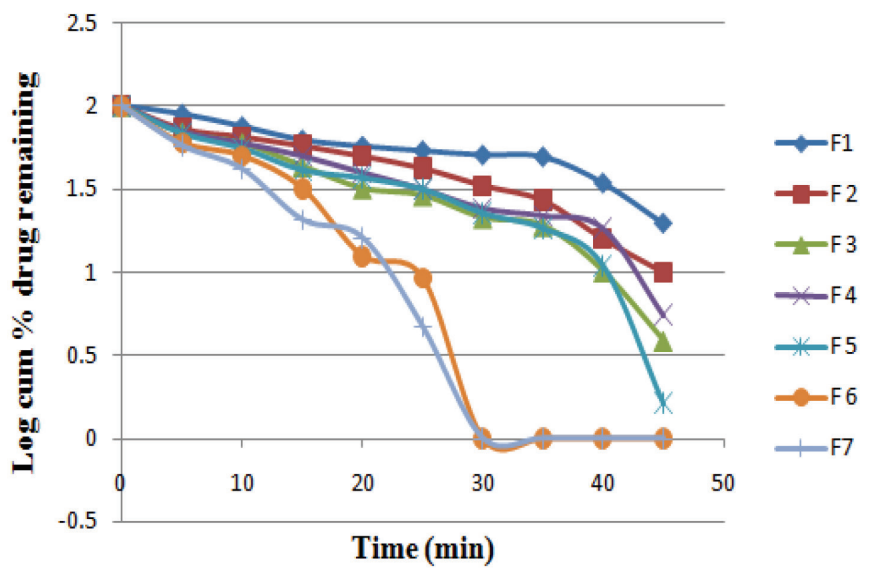

FIGURE 3 - First order release kinetics plot.

TABLE IV - Drug release kinetics ( $\mathrm{R}^{2}$ values of formulations)

\begin{tabular}{lccccccc}
\hline Formulations & F1 & F2 & F3 & F4 & F5 & F6 & F7 \\
\hline Zero order & 0.8824 & 0.8125 & 0.5329 & 0.5900 & 0.5053 & 0.0225 & -0.5311 \\
First order & 0.9176 & 0.9403 & 0.9707 & 0.9582 & 0.9451 & 0.9474 & 0.9156 \\
Higuchi plots & 0.8594 & 0.9556 & 0.9857 & 0.9869 & 0.9893 & 0.8883 & 0.8095 \\
Hixon and Crowell & 0.9180 & 0.9388 & 0.9375 & 0.9216 & 0.9034 & 0.9666 & 0.9719 \\
Korsemeyer peppas plots & 0.9328 & 0.9834 & 0.9858 & 0.9882 & 0.9893 & 0.9159 & 0.9741 \\
\hline
\end{tabular}




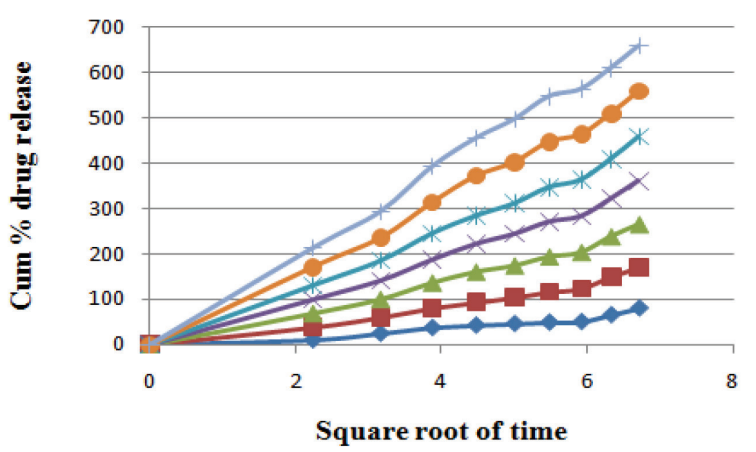

FIGURE 4 - Higuchi model plot.

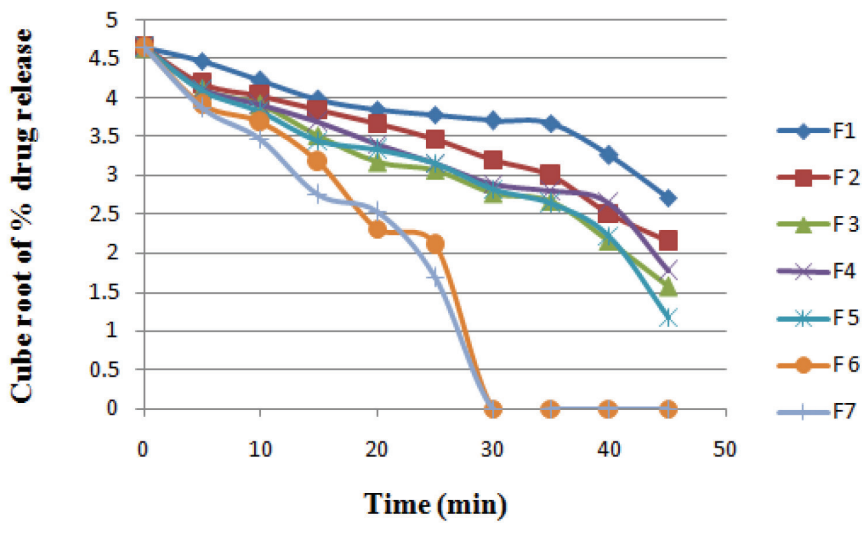

FIGURE 5 Hixon-Crowell model plot.

For the determination of difference of the drug release between the control formulation and the other six formulations t-test and ANOVA were applied on data.

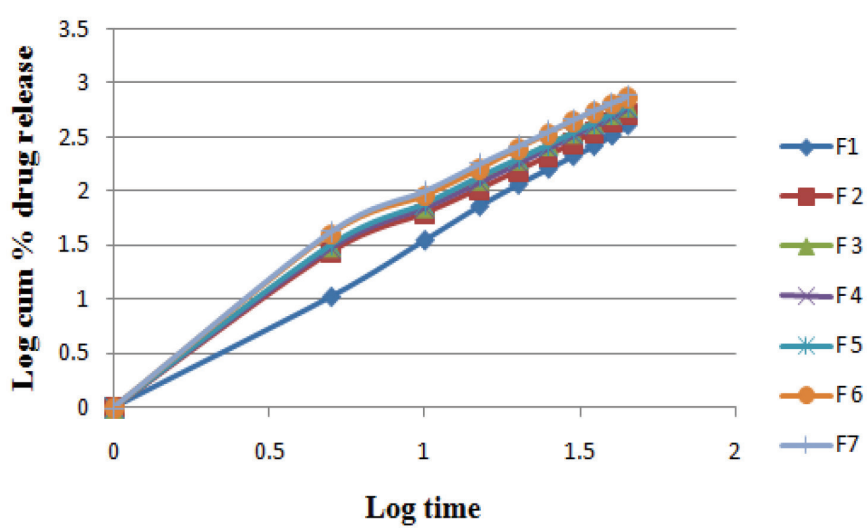

FIGURE 6 - Krosmeyers-Peppas model plot.

ANOVA results are shown in Table $\mathrm{V}$. If $\mathrm{F}$ value is greater than $\mathrm{F}_{\text {crit }}$ value it shows significant difference in drug release profile of different formulations. According to results presented in Table V. F $>\mathrm{F}_{\text {crit }} \mathrm{F}$ value 3.4814 is greater than $\mathrm{F}_{\text {crit }}$ value 2.2655. Therefore results confirm that there is significant difference in drug release of the seven formulations.

$\mathrm{t}$-Test was also performed and results revealed that $\mathrm{t}$ Stat $<\mathrm{t}$ Critical two-tail it means that there is significant difference between the drug release kinetics of the optimized formulations prepared by sublimation technique and the control formulation.

The FT-IR studies revealed that flurbiprofen is compatible with the excipients used in the formulation. There were no extra peaks observed in the IR spectrum. The IR absorption band in $\mathrm{cm}^{-1}$ of the drug and excipients

TABLE V - Results of one way ANOVA

Anova: Single Factor

\begin{tabular}{|c|c|c|c|c|c|c|}
\hline \multicolumn{7}{|c|}{ Anova: Single Factor } \\
\hline \multicolumn{7}{|l|}{ SUMMARY } \\
\hline Groups & Count & Sum & Average & Variance & & \\
\hline Row 1 & 9 & 406.64 & 45.18222 & 418.9677 & & \\
\hline Row 2 & 9 & 528.34 & 58.70444 & 469.3118 & & \\
\hline Row 3 & 9 & 613.41 & 68.15667 & 476.8833 & & \\
\hline Row 4 & 9 & 579.31 & 64.36778 & 438.8329 & & \\
\hline Row 5 & 9 & 613.19 & 68.13222 & 449.5777 & & \\
\hline Row 6 & 9 & 736.6 & 81.84444 & 545.937 & & \\
\hline Row 7 & 9 & 759.27 & 84.36333 & 445.0354 & & \\
\hline \multicolumn{7}{|l|}{ ANOVA } \\
\hline Source of Variation & SS & $\mathrm{Df}$ & MS & $\mathrm{F}$ & P-value & F crit \\
\hline Between Groups & 9682.063987 & 6 & 1613.677 & 3.481455 & 0.005388 & 2.265567 \\
\hline Within Groups & 25956.36691 & 56 & 463.5066 & & & \\
\hline Total & 35638.4309 & 62 & & & & \\
\hline
\end{tabular}


was found to be similar. This established that the drug flurbiprofen and all the excipients used in the study showed no interaction and indicated that they were compatible with each other.

FTIR spectrum of pure FLB show the characteristic peaks shown below: (Sohail et al., 2014)

TABLE VI - Characteristic peaks of flurbiprofen

\begin{tabular}{lc}
\hline Characteristic peaks & Wavelength $\left.\mathbf{( c m}^{-1}\right)$ \\
\hline $\begin{array}{l}\text { Sharp peak representing } \\
(\mathrm{C}=\mathrm{O})\end{array}$ & 1694.9 \\
\hline $\begin{array}{l}\text { Peak representing stretching } \\
\text { of }(\mathrm{C}-\mathrm{F})\end{array}$ & 1215.6 \\
\hline $\begin{array}{l}\text { Characteristic broad peak of } \\
\text { flurbiprofen due to hydrogen } \\
\text { bonding }\end{array}$ & $2,500-3,300$ \\
\hline
\end{tabular}

Visual representation of FTIR spectra of active and powder mixture of best formulations presented in Figure 7- Figure 9.

Stability studies were carried out on optimized formulations $\mathrm{F} 6$ and $\mathrm{F} 7$. Formulations were stored at $40^{\circ} \mathrm{C}$ $\pm 2{ }^{\circ} \mathrm{C} / 75 \pm 5 \% \mathrm{RH}$ for 30 days. No significant changes were found during study period. Thus the formulations were found to be stable.

\section{CONCLUSION}

In conclusion, FDTs of Flurbiprofen were developed that had sufficient mechanical integrity, and uniformity of content. The FDTs were prepared by direct compression method using sublimation technique. All tablets had hardness in the range $5.0-5.4 \mathrm{~kg} / \mathrm{cm}^{2}$ and friability less than $1 \%$. Weight variation and drug content of all formulations were within official limits. In vitro disintegration tests and in vitro drug release studies of FDTs tablets showed that best formulations F6 and F7 containing $10 \%$ and $15 \%$ of Thymol as sublimating agent disintegrate within seconds and the total amount of drug was released within 30 minutes while none of the other formulations showed complete release of the drug within specified time. Hence, the optimized formulations F6 and F7 can be effectively used for the treatment of pain, arthritis and other inflammatory conditions.

\section{CONFLICT OF INTEREST}

The authors confirm that this article content has no conflict of interest.

\section{ACKNOWLEDGEMENTS}

Authors acknowledge Medizan Laboratories

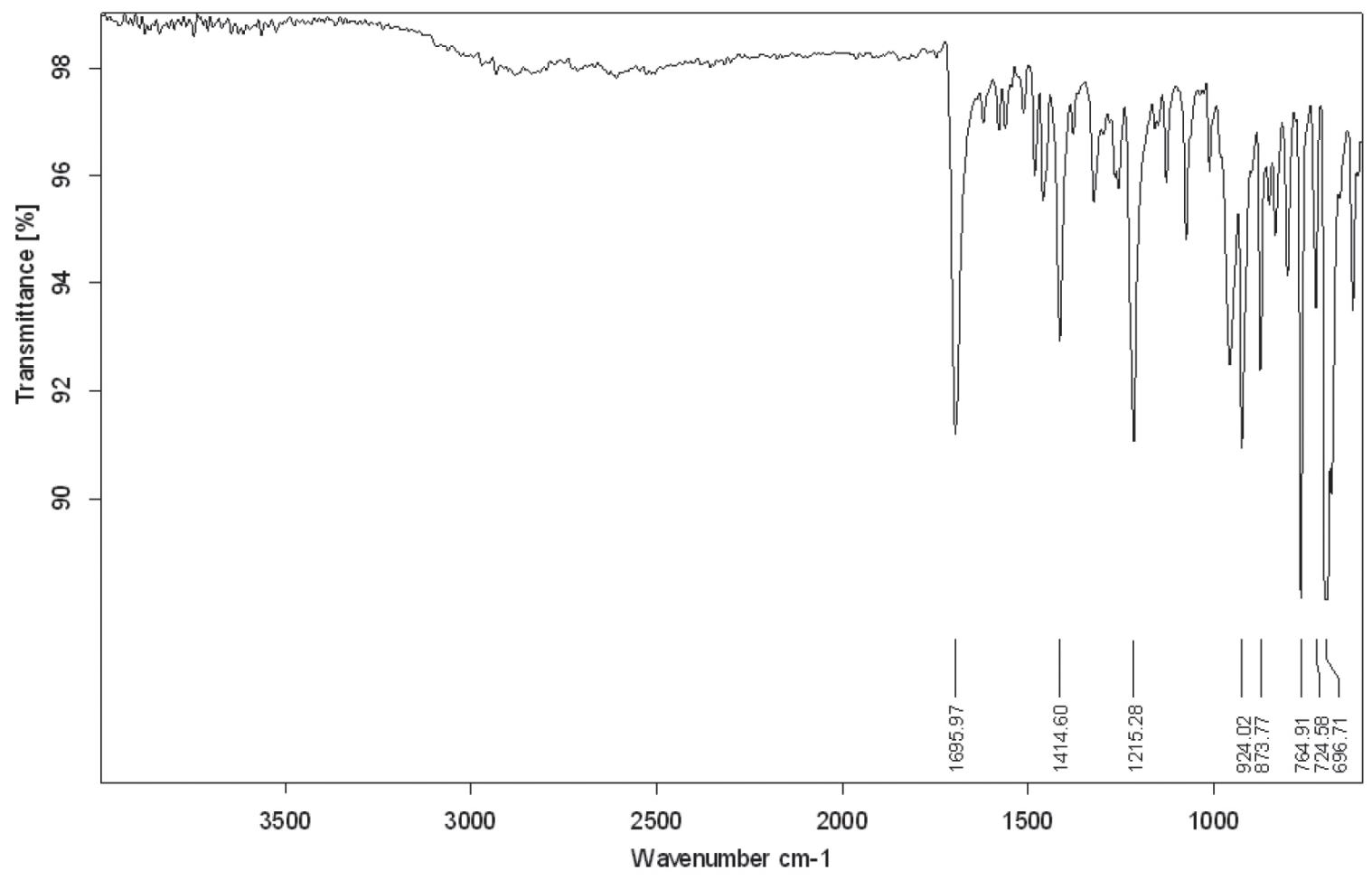

FIGURE 7 - FTIR spectra of flurbiprofen. 


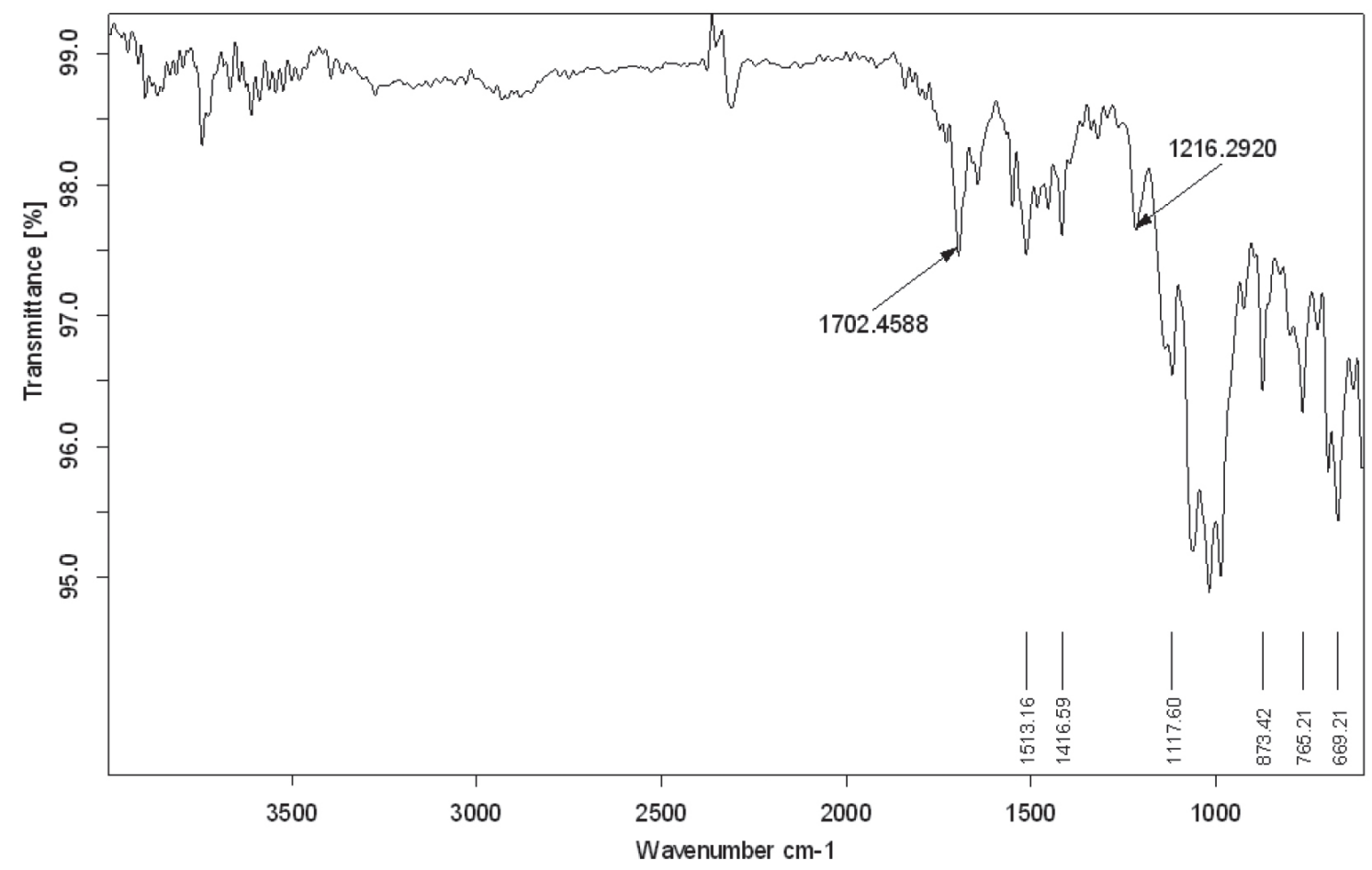

FIGURE 8 - FTIR spectra of formulation F6.



FIGURE 9 - FTIR spectra of formulation F7.

Pakistan for gift samples. The authors are also thankful to Riphah International University (Department of Pharmaceutics) for providing facilities.

\section{REFERENCES}

El-Enin AS. Flurbiprofen fast disintegrating tablets. Inter J Pharm Pharma Sci. 2014;6:499-505. 
Goel H, Rai P, Rana V, Tiwary AK. Orally disintegrating systems: innovations in formulation and technology. Recent Pat Drug Deliv Formul. 2008;2(3):258-74.

Jadhay S, Kaudewar D, Kaminwar G, Jadhay A, Kshirsagar R, Sakarkar D. Formulation and evaluation of dispersible tablets of diltiazem hydrochloride. Int J PharmTech Res. 2011;3(3):131421.

Javed I, Ranjha NM, Massud A, Hussain L. Accelerated stability studies of flurbiprofen film coated tablets of five different national brands in Pakistan. J Drug Deliv Ther. 2013;3(2):9-11.

Kuchekar B, Badhan AC, Mahajan H. Mouth dissolving tablets: A novel drug delivery system. Pharma Times. 2003;35:7-9.

Kumar R, Patil S, Patil M, Patil SR, Paschapur MS. Formulation evaluation of mouth dissolving tablets of fenofibrate using sublimation technique. Int J Chem Tech Res. 2009;1(4):840-50.

Makhija SN, Vavia PR. Once daily sustained release tablets of venlafaxine, a novel antidepressant. Eur J Pharm Biopharm. 2002;54(1):9-15.

Mettu SR, Veerareddy PR. Formulation, evaluation and pharmacokinetics of flurbiprofen fast dissolving tablets. Brit J Pharm Res. 2013;3(4):617-31.

Nagar P, Singh K, Chauhan I, Verma M, Yasir M, Khan A, et al. Orally disintegrating tablets: formulation, preparation techniques and evaluation. J Appl Pharm Sci. 2011;1(04):35-45.
Neau SH, Howard MA, Clausdius JS, Howard DR. The effect of the aqueous solubility of xanthine derivatives on the release mechanism from ethylcellulose matrix tablets. Int J Pharm. 1999;179(1):97-105.

Neduri K, Bontha VK, Vemula SK. Different techniques to enhance the dissolution rate of lovastatin: formulation and evaluation. Asian J Pharm Clin Res. 2013;6:(1):56-60.

Sohail MF, Shah PA, Tariq I, Saeed-ul-Hassan S, Amin U, Raza $\mathrm{SA}$, et al. Development and in vitro evaluation of flurbiprofen microcapsules prepared by modified solvent evaporation technique. Trop J Pharm Res.2014;13(7):1031-8.

Valleri M, Mura P, Maestrelli F, Cirri M, Ballerini R. Development and evaluation of glyburide fast dissolving tablets using solid dispersion technique. Drug Develop Ind Pharm. 2004;30(5):525-34.

Vemula SK, Neduri K. Lovastatin fast dissolving tablets: formulation and in vitro evaluation. App Sci Rep. 2015;11(2):7682 .

Vemula SK, Reddy SG. Formulation and pharmacokinetics of flurbiprofen sublimated fast dissolving tablets. Open Pharm Sci J. 2015;2(1):56-65.

Received for publication on $07^{\text {th }}$ March 2017 Accepted for publication on $14^{\text {th }}$ March 2018 